\title{
Common Comorbidities of Stroke in the Canadian Population
}

\author{
Abdel-Halim Hafez Elamy(D, Ashfaq Shuaib, Keumhee C. Carriere, \\ Thomas Jeerakathil
}

\begin{abstract}
Objectives: Although comorbidity increases the health care and community support needs for patients, and the burden for the health care system, there are few population-based studies on comorbidity in patients with stroke. This study aims to evaluate the occurrence of important comorbidities among stroke patients in the Canadian population. Methods: Data from the population-based 2011-2012 Canadian Community Health Survey containing responses from 124,929 participants covering about $98 \%$ of the Canadian population when weighted were examined and analyzed by means of logistic regression models. Results: There was a statistically significant association between stroke history and multiple comorbid risk factors. Stroke prevalence increased in individuals with heart disease (odds ratio (OR): 3.80, 95\% confidence interval (CI): 3.77-3.84), hypertension (OR: 1.97, 95\% CI: 1.95-1.99), diabetes (OR: 1.74, 95\% CI: 1.72-1.75), mood disorder (OR: 2.14, 95\% CI: 2.12-2.17), and chronic obstructive pulmonary disease (COPD) (OR: 1.46, 95\% CI: 1.44-1.48) compared to others without the condition. Of 2067 participants with stroke, $1680(81.3 \%)$ had one or more comorbid conditions (heart disease, hypertension, diabetes, mood disorder, or COPD) that coexist with stroke and $48 \%$ had two or more. Comorbidity increased with age, and two-thirds of stroke patients with comorbid medical conditions were 60 years of age or older. Conclusion: This population-based study provides evidence of comorbidity between stroke and other conditions that include heart disease, hypertension, diabetes, mood disorder, and COPD. Canadian individuals with stroke have a high burden of comorbidity. Health care systems need to recognize and respond to the strong association of comorbidity and stroke occurrence. This key factor should be considered when allocating resources.
\end{abstract}

RÉSUMÉ : Les comorbidités les plus couramment associées aux AVC au sein de la population canadienne. Objectifs : Bien que la présence de comorbidités chez les victimes d'AVC tende à augmenter la charge pour le système de santé ainsi que le soutien et les soins dont elles ont besoin, en particulier à un niveau communautaire, il existe peu d'études populationnelles portant sur ces mêmes comorbidités. Cette étude entend donc évaluer la fréquence de comorbidités importantes parmi les Canadiens victimes d'un AVC. Méthodes : Pour ce faire, nous avons fait appel aux données tirées de l'Enquête sur la santé dans les collectivités canadiennes pour l'année 2011-2012. Ces données ont été extraites des réponses de 124929 participants. Une fois pondérées, elles couvrent $98 \%$ de la population canadienne. Nous les avons examinées et analysées à l'aide de modèles de régression logistique. Résultats : Tout d'abord, on a remarqué qu'il existait une association statistiquement significative entre le fait d'avoir des antécédents d'AVC et de multiples facteurs de risque liés à des comorbidités. En comparaison avec des individus chez qui des comorbidités n'étaient pas présentes, la prévalence des AVC a augmenté chez ceux atteints de maladies du cœur (rapport des cotes : 3,80 ; IC $95 \%: 3,77-3,84$ ), d'hypertension (rapport des cotes : 1,97 ; IC $95 \%: 1,95-1,99$ ), de diabète (rapport des cotes : 1,74 ; IC $95 \%: 1,72-1,75$ ), de troubles de l'humeur (rapport des cotes : 2,14; IC 95\%:2,12-2,17) et de bronchopneumopathie chronique obstructive (BPCO) (rapport des cotes : 1,46; IC $95 \%: 1,44-1,48$ ). Sur 2067 participants victimes d'un AVC, 1680 d'entre eux $(81,3 \%)$ ont signalé une comorbidité ou plus (maladie du cœur, hypertension, diabète, trouble de l'humeur ou BPCO) alors que $48 \%$ d'entre eux en ont signalé deux ou plus. Ajoutons aussi que les comorbidités ont tendance à augmenter avec l'âge et que les deux-tiers des individus victimes d'un AVC qui en avaient signalé au moins une étaient âgés de 60 ans ou plus. Conclusion : Cette étude populationnelle fournit ainsi la preuve qu'il existe un lien entre les AVC et d'autres problèmes de santé, ce qui inclut les maladies du cœur, l'hypertension, le diabète, les troubles de l'humeur et la BPCO. Les Canadiens victimes d'un AVC courent donc un risque plus élevé de souffrir d'un ou plusieurs de ces problèmes. Il s'ensuit que les systèmes de santé doivent reconnaître cette forte association et pouvoir y répondre, ce qui devrait être pris en compte au moment de l'allocation des ressources.

Keywords: Stroke, Comorbidity, Multimorbidity, Logistic regression, CCHS, Stratified sampling 


\section{INTRODUCTION}

Comorbidity denotes the simultaneous presence of at least two medical conditions in the same individual that are associated with each other through pathogenetic mechanisms and occur more frequently than it would be expected by chance. In contrast, multimorbidity is another term that denotes the simultaneous presence of two or more medical conditions that occur randomly in the same individual without necessarily having any connection to each other through pathogenetic mechanisms. ${ }^{1-3}$ In stroke patients, comorbidity may create substantial prognostic differences that mislead statistics on mortality and patient outcomes because death or incapacitation may be due to comorbid illnesses rather than due to stroke alone. Thus, the comorbid effects must be carefully considered when patients are stratified for therapeutic comparisons and evaluation in medical research as well as in health care services.

In this study, we aimed to investigate the prevalence and significance of comorbid conditions occurring among Canadians suffering from previous strokes as primary ailments. Heart disease, hypertension, diabetes, mood disorder, and chronic obstructive pulmonary disease (COPD) were investigated as potential comorbid conditions that are linked to the occurrence of stroke. Evaluating these conditions and studying their association with stroke will be crucial for better understanding the needs of this patient group and, consequently, allocating health care resources more efficiently.

\section{Materials ANd Methods}

Data were drawn from the 2011-2012 Canadian Community Health Survey (CCHS). The CCHS is a national cross-sectional survey conducted and administered by Statistics Canada to collect information on health determinants, health status, and health care utilization for Canadians. As part of the National Population Health Study on Neurological Conditions ${ }^{4}$, a special module on neurological conditions was added to the 2011-2012 CCHS cycle which asked respondents if they or anyone living in their household had any neurological conditions that included stroke. The target populations for these cross-sectional surveys were all Canadians aged 12 years and older living in the provinces and territories. Individuals living on Indian Reserves and on Crown Lands, institutional residents, full-time members of the Canadian Armed Forces, and residents of some remote regions were excluded from participation in the surveys.

\section{Sampling}

Data collected from a sample survey are used to produce estimates for the target population. To assure adequate representation of the Canadian population, the CCHS used a multistage stratified cluster design for sampling. ${ }^{5}$ In this design, three sampling cohorts (statistically known as "frames") are used to select surveyed units (households). Then, one person is chosen at random from each household to complete the survey after applying a set of probabilities that consider the age of the respondent and the household composition. In some cases, two persons are selected when the household is large. Béland et al. ${ }^{6}$ provided justifications for the approach and the exact algorithm.

Half of the sample respondents came from an area frame that is based on household information gathered from another survey, the
Canadian Labour Force Survey. ${ }^{7}$ Those respondents were interviewed in person. Another $49 \%$ of all respondents were selected from a list frame of telephone numbers of households in all health regions listed in the Canadian Telephone Directory database. The remaining $1 \%$ of the respondents came from a Random Digit Dialing (RDD) sampling frame. Respondents selected from the telephone list frame and the RDD frame were interviewed through centralized call centers supervised by senior interviewers.

The CCHS sample we used in this study covers approximately $98 \%$ (after weighting) of the Canadian population with a response rate that ranged from high $(84.7 \%$ in 2001$)$ to low $(67.0 \%$ in 2012) ${ }^{8-10}$ Additional details about the CCHS sampling and other measurement concepts can be found in the CCHS catalogs published by Statistics Canada. ${ }^{7}$

\section{Weighting}

Each respondent in the CCHS data "represents," besides himself or herself, several other people who are not included in the sample. For instance, in a $2 \%$ simple random sample of the population, each person in the sample represents 50 people in the population. That is, each person in the sample has a weight of 50 . Thus, if the number of stroke survivors is to be estimated, we must select the records referring to those individuals in the sample and summing up their weights. The main reason for assigning weights is to compensate for unequal selection probabilities and nonresponse bias. This bias occurs when a selected household refuses to participate in the survey, cannot be reached for an interview, or cannot complete all stages of the survey. For example, in 2010 CCHS survey, out of 88,410 chosen households, 17,095 refused to participate resulting in an overall nonresponse rate of $19.3 \%$. Those households were removed from the sample, and their weights were redistributed to responding households. ${ }^{11}$ Due to its design complexity and its crosssectional nature, the CCHS weighting process involves several steps of adjustments.

The CCHS dataset we used in this study contains information collected from 124,929 participants who provided responses to a 1207 variable questionnaire. ${ }^{9,10}$ After excluding children under 18 , a modified sample of 114,474 individuals aged 18 years and older was adopted. The weighted sample represents a total number of 26,897,385 Canadians.

Comorbidity variables (heart disease, hypertension, diabetes, mood disorder, and COPD) representing responses on selfreported comorbid conditions were used as predictors for stroke and coded dichotomously with two levels- "Yes" and "No." We adjusted these variables by a set of demographic and lifestyle variables: sex, age, smoking, physical activity, and body mass index (BMI) that we considered as potential confounders. Table 1 provides information on the baseline variables compared by stroke prevalence.

Simple and multiple logistic regression models were adopted to determine the significance of comorbid risk factors in question. We verified the goodness of fit (Hosmer-Lemeshow test and receiver operating characteristic (ROC) curve analysis) and other logistic regression assumptions (e.g., independence of errors and lack of collinearity). All analyses were conducted using SPSS (Copyright IBM Corp, Armonk, NY, USA). A $p$-value of 0.05 was used as a cut-off level of significance. 
Table 1: Baseline variables compared by stroke prevalence in the Canadian population (weighted)

\begin{tabular}{|c|c|c|c|c|}
\hline \multirow{2}{*}{ Variables } & History of stroke & Population & No history of stroke & Total \\
\hline & $(n=331,693)$ & Proportion & $(N=28,927,603)$ & $N=29,259,296$ \\
\hline Heart disease & $118,982(35.9 \%)^{\mathrm{a}}$ & $0.4 \%^{\mathrm{a}}$ & $1,304,893(4.5 \%)^{\mathrm{b}}$ & $1,423,821^{\mathrm{b}}$ \\
\hline Hypertension & $186,032(56.1 \%)$ & $0.6 \%$ & $4,916,775(17.0 \%)$ & $5,102,807$ \\
\hline Diabetes & $84,937(25.5 \%)$ & $0.3 \%$ & $1,769,032(6.1 \%)$ & $1,853,969$ \\
\hline Mood disorder & $55,582(16.7 \%)$ & $0.2 \%$ & $2,015,012(7.0 \%)$ & $2,070,594$ \\
\hline COPD & $37,951(12.1 \%)$ & $0.2 \%$ & $752,603(4.0 \%)$ & 790,554 \\
\hline Sex (female) & $168,374(50.5 \%)$ & $0.6 \%$ & $14,675,710(50.6 \%)$ & $14,844,084$ \\
\hline \multicolumn{5}{|l|}{ Age (years) } \\
\hline $80+$ & $67,741(20.3 \%)$ & $0.2 \%$ & $1,018,000(3.5 \%)$ & $1,085,741$ \\
\hline $60-79$ & $180,275(54 \%)$ & $0.6 \%$ & $5,662,812(19.5 \%)$ & $5,843,087$ \\
\hline$<60$ & $85,586(25.7 \%)$ & $0.3 \%$ & $22,294,130(76.9 \%)$ & $22,379,716$ \\
\hline \multicolumn{5}{|l|}{ Smoking } \\
\hline Daily & $57,824(17.6 \%)$ & $0.2 \%$ & $4,389,945(15.3 \%)$ & $4,447,769$ \\
\hline Occasional & $8514(2.6 \%)$ & $0.03 \%$ & $1,384,334(4.8 \%)$ & $1,392,848$ \\
\hline Former smoker & $154,870(47 \%)$ & $0.5 \%$ & $10,679,094(37.1 \%)$ & $10,833,964$ \\
\hline Never smoked & $108,117(32.8 \%)$ & $0.4 \%$ & $12,327,567(42.8 \%)$ & $12,435,684$ \\
\hline $\begin{array}{l}\text { Physical activity } \\
\text { (inactive) }\end{array}$ & $188,433(1.4 \%)$ & $0.7 \%$ & $13,072,550(46 \%)$ & $13,260,983$ \\
\hline BMI (overweight/obese) & $116,562(43.6 \%)$ & $0.5 \%$ & $11,400,060(46.4 \%)$ & $11,516,622$ \\
\hline
\end{tabular}

${ }^{\mathrm{a}}$ Of the 331,693 individuals suffering from the effects of stroke, $118,982(35.9 \%)$ had heart diseases. This represents $0.4 \%$ of the entire weighted population $(118,982 \div 29,259,296)$.

${ }^{\mathrm{b}}$ Of the $1,423,821$ individuals with heart diseases, 1,304,389 did not have a history of stroke. This represents $4.5 \%$ of the entire weighted population $(1,304,389 \div 29,259,296)$.

\section{RESUlts}

In our dataset, 2067 positive responses of stroke cases were identified - 984 (47.6\%) males and 1083 (52.4\%) females. This corresponds to a total weighted count of $331,488(1.23 \%)$ prevalent cases of individuals suffering from the effects of stroke in the entire population of Canadians aged 18 years and older during the time of collection.

Of the 2067 respondents with stroke, 1680 (81.3\%) individuals had one or more comorbid conditions (heart disease, hypertension, diabetes, mood disorder, and COPD) that coexist with stroke. Figure 1 illustrates the distribution of comorbidities by age group. Two-thirds of stroke patients with comorbid medical conditions were 60 years of age or older. We also found that $696(34 \%)$ of stroke patients were suffering from one of the comorbid conditions in question, 600 (29\%) were suffering from two, 287 (14\%) were suffering from three, and 97 (5\%) were suffering from four comorbid conditions.

Table 2 demonstrates the results of univariate (unadjusted) and multivariable (adjusted) logistic regressions. After controlling for confounders, it was evident that all comorbid conditions were associated with stroke. The odds of prevalent stroke ranged from nearly four-fold higher for individuals with heart diseases to about 1.50 times higher for individuals with COPD compared to others without the condition. The area under the ROC curve was 0.80 (95\% confidence interval: $0.78-0.81)$, revealing reasonable accuracy of tests. The Hosmer-Lemeshow test $p$-value was
$>>0.2$, which suggests sufficient goodness of fit of the logistic regression models used.

\section{Discussion}

We have demonstrated the extent of comorbidity between stroke and several other medical conditions (heart disease, hypertension, diabetes, mood disorder, and COPD) in a community dwelling Canadian population. These comorbid conditions have a complex relationship with stroke. Our findings extend and confirm previous findings reported in other studies. ${ }^{12-14}$ Hypertension and diabetes, in addition to being comorbidities, are also wellrecognized risk factors for stroke. ${ }^{15}$ The duration of diabetes is also an important factor that contributes to the risk of stroke. ${ }^{16}$ Cardiovascular diseases and COPD share some risk factors with stroke and are themselves risk factors for stroke. ${ }^{17,18}$ In addition, there is growing evidence that mood disorders, including depression and psychosocial stress, increase the risk of stroke incidence and stroke mortality. ${ }^{19-21}$ Moreover, mood disorder is a very common and serious complication after stroke with $30 \%$ of stroke patients experiencing depression, both early and late following stroke. $^{22,23}$

In unselected patient and community groups, comorbidity predicts a host of adverse outcomes such as progressive loss of mobility, poor functional status, and mortality. ${ }^{24}$ There has been little study of the effect of comorbidity on outcomes in stroke 


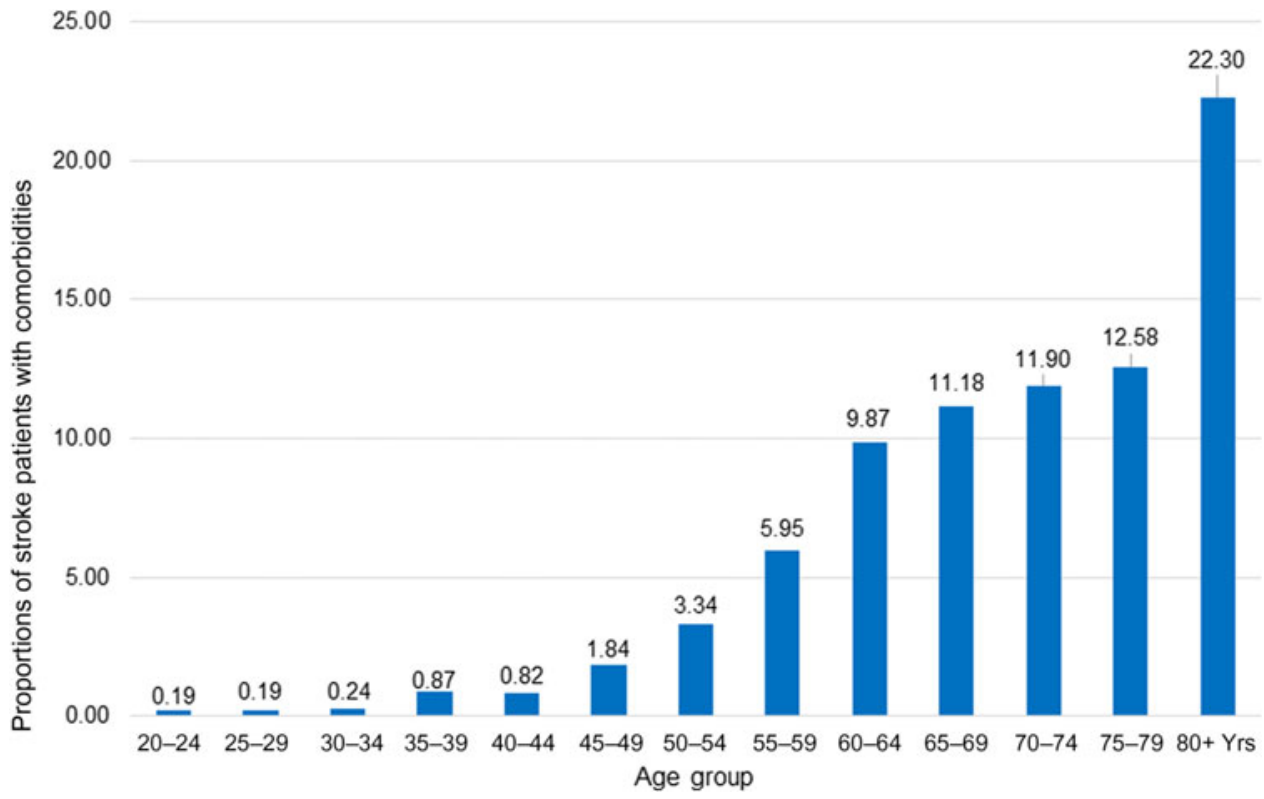

Figure 1: Proportions of stroke patients with comorbidities.

Table 2: Results of univariate (unadjusted) and multivariable (adjusted) logistic regression models investigating the comorbid conditions associated with stroke

\begin{tabular}{|c|c|c|}
\hline \multirow{2}{*}{ Condition } & \multicolumn{2}{|c|}{ Odds ratio $(95 \% \mathrm{CI}), p$-value (weighted) } \\
\hline & Univariate & Multivariable \\
\hline Heart disease & $11.84(11.76-11.93),<0.001$ & $3.80(3.77-3.84),<0.001$ \\
\hline Hypertension & $6.22(6.12-6.26),<0.001$ & 1.97 (1.95-1.99), <0.001 \\
\hline Diabetes & $5.26(5.21-5.30),<0.001$ & $1.74(1.72-1.75),<0.001$ \\
\hline Mood disorder & $2.68(2.65-2.70),<0.001$ & $2.14(2.12-2.17),<0.001$ \\
\hline COPD & $3.30(3.27-3.34),<0.001$ & $1.46(1.44-1.48),<0.001$ \\
\hline Sex (male) & $1.00,0.04$ & Not significant \\
\hline \multicolumn{3}{|l|}{ Age (years) ${ }^{\dagger}$} \\
\hline \multicolumn{3}{|l|}{$<60$} \\
\hline $80+$ & $17.34(17.16-17.51),<0.001$ & $5.10(4.99-5.13),<0.001$ \\
\hline $60-79$ & $8.29(8.23-8.36),<0.001$ & $3.64(3.60-3.68),<0.001$ \\
\hline \multicolumn{3}{|l|}{ Smoking $^{\dagger}$} \\
\hline \multicolumn{3}{|l|}{ Never smoked } \\
\hline Daily & $1.50(1.49-1.52),<0.001$ & $1.42(1.41-1.44),<0.001$ \\
\hline Occasional & $0.70(0.69-0.72),<0.001$ & $1.10(1.07-1.13),<0.001$ \\
\hline Former smoker & $1.65(1.64-1.67),<0.001$ & $0.92(0.91-0.93),<0.001$ \\
\hline Physical activity (inactive*) & $2.29(2.27-2.31),<0.001$ & $1.53(1.51-1.54),<0.001$ \\
\hline BMI (overweight/obese**) & $1.12(1.11-1.13),<0.001$ & $1.48(1.46-1.49),<0.001$ \\
\hline
\end{tabular}

${ }^{\dagger}$ Reference.

$*$ Reference $=$ Active.

$* *$ Reference $=$ Normal weight.

patients other than comorbidity indexes predicting mortality in acute stroke inpatients. $^{25}$

Comorbidity is clearly related to age with the occurrence tripling in those $35-45$ years of age compared to younger groups but remaining less than $1 \%$ (Figure 1). The occurrence of comorbidity then seems to almost double with every subsequent 5-year span of age before plateauing between years 60-79 at approximately $10-12 \%$ then almost doubling again after age 80 . 
Quantifying the prevalence of comorbid conditions in stroke patients, particularly those age 60 and above, offers a starting point toward understanding their complexity and impact on the health system. This characterization can be extended to include further information on such a category of patients (e.g., the frequency of hospitalizations and emergency visits and other conditions). As the population ages, health care practitioners and policy makers need to understand the implications of comorbidity in persons with stroke to better plan services to meet their needs.

Comorbidity is associated with poorer health outcomes, complex clinical management, and substantially increased resource use. In the USA, almost $80 \%$ of Medicare spending is devoted to patients with four or more chronic conditions, with costs increasing exponentially as the number of conditions increases. ${ }^{26}$ The quantification of this association is crucial to support the design of health care programs targeted toward stoke prevention. Moreover, health care practitioners need to be wary of additional complexities in the treatment of individuals with stroke in tandem with multiple coexisting diseases.

The strengths of this study include using a population-based national survey representing nearly the entire population of Canadian adults and conducting robust statistical analyses. The study is limited by its cross-sectional nature that allows us to determine association and not causation. The lack of availability of timing of exposures limits the opportunity to investigate causality. Misclassification of disease status and recall bias may also be present due to self-reporting.

In summary, up to $81 \%$ of Canadian stroke survivors have comorbid medical conditions. Additional research is needed to examine the link between comorbidity and health outcomes in stroke survivors including cerebrovascular disease recurrence and functional status.

\section{ACKNowledgments}

The authors would like to thank Prof. Christopher McCabe for reviewing the manuscript and providing valuable comments and suggestions to improve its quality.

\section{FuNDING}

Abdel-Halim Hafez Elamy received scholarship funding from the University of Alberta and the QuICR Thomas Feasby/Alberta Innovates Health Solutions while implementing this study. Thomas Jeerakathil has received honoraria from Bayer for one advisory board meeting in the last five years and grant support from Canadian Institutes of Health Research, Alberta Innovates Health Solutions, The Heart and Stroke Foundation of Canada, Canadian Stroke Network, and Alberta Health Services.

\section{CONFLict of InTERest}

The authors declare that there is no conflict of interest to report.

\section{Statement of Authorship}

AHE conceived, designed, and carried out the study, analyzed the data, carried out the statistical analysis, and wrote the manuscript. TJ directed the study, obtained funding, advised on the design and structure, revised all versions of the manuscript, and reviewed the results. AS commented on the manuscript, provided critical revision on its structure, and reviewed the results. KCC reviewed the manuscript and provided critical advice on the analysis of the CCHS data and the statistical methods used. All authors reviewed and edited the manuscript and approved the final version of the manuscript.

\section{Ethical Approval}

This is a substudy of a larger project with ethics approval and waiver of consent due to de-identified and publicly available data collected and released by Statistics Canada.

\section{REFERENCES}

1. Jakovljevic M, Ostojic L. Comorbidity and multimorbidity in medicine today: challenges and opportunities for bringing separated branches of medicine closer to each other. Psychiatr Danub. 2013;25(Suppl 1):18-28.

2. Jakovljević M, Crnčević Ž. Comorbidity as an epistemological challenge to modern psychiatry. 2012

3. Aragona M. The role of comorbidity in the crisis of the current psychiatric classification system. Philos, Psychiat, \& Psychol. 2009;16(1):1-11.

4. Caesar-Chavannes C, MacDonald S. Cross-Canada ForumNational Population Health Study of Neurological Conditions in Canada. Chronic Dis Inj Canada 2013;33(3):188-91.

5. Allen M, Kilpatrick D, Armstrong M, Briggs R, Course G, Pérez N. Multistage cluster sampling design and optimal sample sizes for estimation of fish discards from commercial trawlers. Fish Res. 2002;55(1-3):11-24.

6. Béland Y, Bailie L, Catlin G, Singh M. CCHS and NPHS - an improved health survey program at Statistics Canada. Paper presented at: Proceedings of the American Statistical Association Meeting, Survey Research Methods 2000.

7. Canada S. Methodology of the Canadian Labour Force Survey. Cat. No. 71-526-X. Statistics Canada Ottawa; 2017.

8. Veenstra G, Patterson AC. Black-White Health Inequalities in Canada. Journal of Immigrant and Minority Health. 2016;18(1): $51-57$.

9. Canada S. Canadian Community Health Survey, 2011-2012: Annual Component. Statistics Canada. 2013;cchs-82M0013-E2011-2012-Annual-component.

10. Béland Y. Canadian community. Health Rep. 2002;13(3):9-14.

11. Chatrchi G, Duval M-C, Brisebois F, Thomas S. The impact of typical survey weighting adjustments on the design effect: A case study. Survey Methods: Insights from the Field. 2015:15.

12. Nacu A, Fromm A, Sand KM, Waje-Andreassen U, Thomassen L, Næss H. Age dependency of ischaemic stroke subtypes and vascular risk factors in western Norway: the Bergen Norwegian Stroke Cooperation Study. Acta Neurologica Scandinavica. 2016;133(3):202-7.

13. Jeerakathil T, Wolf PA, Beiser A, et al. Stroke risk profile predicts white matter hyperintensity volume. Stroke. 2004;35(8):1857-61.

14. De Leeuw FE, De Groot JC, Oudkerk M, et al. A follow-up study of blood pressure and cerebral white matter lesions. Ann Neurol. 1999;46(6):827-33.

15. Lavy S, Melamed E, Cahane E, Carmon A. Hypertension and diabetes as risk factors in stroke patients. Stroke. 1973;4(5): 751-9.

16. Banerjee C, Moon YP, Paik MC, et al. Duration of diabetes and risk of ischemic stroke The Northern Manhattan Study. Stroke. 2012;43(5):1212-7.

17. Austin V, Crack PJ, Bozinovski S, Miller AA, Vlahos R. COPD and stroke: are systemic inflammation and oxidative stress the missing links? Clin Sci. 2016;130(13):1039-50.

18. Feary JR, Rodrigues LC, Smith CJ, Hubbard RB, Gibson JE. Prevalence of major comorbidities in subjects with COPD and incidence of myocardial infarction and stroke: a comprehensive 
analysis using data from primary care. Thorax. 2010;65(11): 956-62.

19. Folstein MF, Maiberger R, McHugh PR. Mood disorder as a specific complication of stroke. J Neurol, Neurosurg Psychiat. 1977; 40(10): 1018-20.

20. Aström M, Adolfsson R, Asplund K. Major depression in stroke patients. A 3-year longitudinal study. Stroke. 1993;24(7): 976-82.

21. Astroöm M. Generalized anxiety disorder in stroke patients: a 3-year longitudinal study. Stroke. 1996;27(2):270-5.

22. Williams LS, Ghose SS, Swindle RW. Depression and other mental health diagnoses increase mortality risk after ischemic stroke. Am J Psychiatry 2004;161(6):1090-5.
23. Everson SA, Roberts RE, Goldberg DE, Kaplan GA. Depressive symptoms and increased risk of stroke mortality over a 29 -year period. Arch Int Med. 1998;158(10):1133-8.

24. John R, Kerby DS, Hagan Hennessy C. Patterns and impact of comorbidity and multimorbidity among community-resident American Indian elders. The Gerontologist. 2003;43(5): 649-60.

25. Liu M, Domen K, Chino N. Comorbidity measures for stroke outcome research: a preliminary study. Arch Physical Med Rehabilit. 1997;78(2):166-72.

26. Wolff JL, Starfield B, Anderson G. Prevalence, expenditures, and complications of multiple chronic conditions in the elderly. Arch Int Med. 2002;162(20):2269-76. 